\title{
AVALIAÇÕES MORFOFISIOLÓGICAS NA FASE VEGETATIVA DE MILHO IRRIGADO
}

Ana Carolina Mônico Moreira, Catariny Cabral Aleman

Universidade do Oeste Paulista - UNOESTE, Faculdade de Agronomia, Presidente Prudente - SP. E-mail: catariny@unoeste.br

\section{RESUMO}

O milho é uma cultura de grande importância econômica na agricultura brasileira e mundial. O suprimento de água é importante para seu crescimento e desenvolvimento desde que adotado na quantidade adequada para atender as necessidades hídricas da planta. O presente trabalho objetivou avaliar a resposta fisiológica e bioquímica de um cultivar de milho transgênico e um híbrido submetidos a diferentes lâminas de irrigação. O trabalho foi conduzido em ambiente protegido, no campus II da Unoeste, Presidente Prudente - SP. O delineamento experimental foi em blocos ao acaso em esquema fatorial duplo, com cinco lâminas de irrigação $(150,100,75,50$ e 25\% evapotranspiração da cultura (ETc)), 2 cultivares (transgênico (Agroceres 8088) e PEN 22 robusto (Selegrãos)) e 4 blocos. As lâminas de irrigação foram determinadas em função de leituras diárias do evaporímetro de Pichê ajustadas pelo coeficiente de cultura (kc) de 1,2 para a cultura do milho. Os parâmetros avaliados foram altura de plantas (quinzenalmente), comprimento e volume de raiz, massa seca de parte aérea e raiz, relação raiz/parte aérea e concentração de prolina nas folhas frescas. Os dados foram submetidos à ANOVA e posteriormente ao teste de Tukey para comparação entre as médias ao nível de probabilidade de 0,05. Para as condições do Oeste Paulista, é mais viável o plantio do cultivar da PEN 22 Robusta com irrigação de $25 \%$ da evapotranspiração da cultura (ETc) por garantir acúmulo de biomassa na fase de desenvolvimento vegetativo.

Palavras-chave: estresse hídrico; fase de desenvolvimento; irrigação.

\section{REVIEWS MORPHOPHISIOLOGICAL IN VEGETATIVE PHASE OF IRRIGATED CORN}

\begin{abstract}
Corn is a crop of great economic importance in the Brazilian and world agriculture. The water supply is important for their growth and development from that adopted in the proper amount to meet the water needs of the plant. This study aimed to evaluate the physiological and biochemical response of a cultivar of transgenic corn and a hybrid subjected to different irrigation. The work was conducted in greenhouse on campus Unoeste II, Presidente Prudente - SP. The experimental design was in randomized blocks in a double factorial design with five depth of irrigation $(150,100$, 75, 50 and 25\% crop evapotranspiration (ETc)), two cultivars (transgenic Agroceres 8088 and robust 22 PEN (Selegrãos)) and 4 blocks. The depths of irrigation were determined according to the daily readings evaporimeter tar adjusted by the crop coefficient $(\mathrm{kc})$ of 1.2 for the corn crop. The parameters evaluated were plant height, length and root volume, dry weight of shoot and root, root / shoot ratio and shoot proline concentration in fresh leaves. Data were submitted to ANOVA and then Tukey test to compare means between the probability level of 0.05 . For the conditions of Oeste Paulista, is more feasible planting cultivar of PEN 22 Robust irrigation with $25 \%$ of crop evapotranspiration (ETc) for ensuring biomass accumulation in the vegetative stage.
\end{abstract}

Key-words: hydric stress; vegetative stage; irrigation. 


\section{INTRODUÇÃO}

O milho (Zea mays L.) representa um dos principais cereais cultivados no mundo, fornecendo produtos para alimentação humana, animal e matéria prima para a indústria, principalmente pelas reservas energéticas acumuladas em seus grãos (FERREIRA et al., 2011).

Segundo Pavinato et al. (2008) o cultivo do milho sob irrigação aumentou significativamente, promovendo algumas alterações no manejo das lavouras, através do planejamento de uso mais intensivo das áreas para compensação do alto investimento, com maior número de cultivos e culturas envolvidas. A expansão das lavouras irrigadas tem exigido aumento da demanda de conhecimento com relação ao manejo de irrigação para a obtenção de altas produtividades que favoreçam a viabilidade econômica.

A água é um dos fatores mais indispensáveis para a produção agrícola, atuando no metabolismo com reflexos positivos ao crescimento, desenvolvimento e produção vegetal. É importante que os recursos hídricos sejam utilizados de forma racional para garantir a sustentabilidade e maximização da produção (BENJAMIN et al., 2014). A adoção de técnicas racionais de manejo conservacionista do solo e da água são de fundamental importância para a sustentabilidade, de tal forma que se possa, economicamente, manter ao longo do tempo esses recursos com quantidade e qualidade suficientes para a manutenção de níveis satisfatórios de produtividade (CARMO et al., 2012; BRITO et al., 2013). A irrigação está entre os tratos culturais que constitui uma alternativa viável para aumento da produtividade, atendendo às necessidade hídricas da cultura, principalmente, em épocas de falta de água (LOPES et al., 2011).

$$
\text { O déficit hídrico e a reduzida }
$$
capacidade de retenção de água no solo são fatores que prejudicam o crescimento e desenvolvimento da planta. Em determinadas fases de desenvolvimento, a falta de água pode comprometer a produção final. Diante disso, o objetivo desse trabalhou foi avaliar a resposta fisiológica e bioquímica de 2 cultivares comerciais de milho irrigados com lâminas de irrigação com déficit e excesso.

\section{MATERIAL E MÉTODOS}

O experimento foi conduzido em ambiente protegido telado coberto com plástico transparente sem controle de umidade e temperatura, no campus II, localizado na Rodovia Raposo Tavares km 572 , a uma latitude de $22^{\circ} 07^{\prime} 04^{\prime \prime} \mathrm{S}$ e longitude de $51^{\circ} 22^{\prime} 04^{\prime \prime} \mathrm{W}$, aproximadamente a 432 metros acima do nível do mar. O clima da região é caracterizado, segundo Köppen, como AW mesotérmico, com verões quentes 
e invernos secos. O solo é classificado como Argissolo Vermelho - Amarelo, Eutrófico de textura arenosa/média (EMBRAPA, 1999).

O delineamento experimental foi em blocos ao acaso com esquema fatorial duplo. Totalizaram 40 unidades experimentais, sendo utilizados dois cultivares de milho e 5 lâminas de irrigação com 4 blocos para cada tratamento.

Os cultivares de milho utilizado foram: o transgênico (Agroceres 8088) e o PEN 22 robusto (Selegrãos). O milho foi plantado em vasos com dimensões de $35 \times 20 \mathrm{~cm}$, preenchido com solo. Antes do preparo dos vasos, foi realizada análise físico química do solo no Laboratório de Solos da Universidade do Oeste Paulista (Tabela 1). A granulometria de $79,5 \%$ de areia; $14 \%$ argila e $6,5 \%$ de silte caracterizando Classe Textural Arenosa. A correção do solo foi feita de acordo com Van Raij et al. (1997).

Tabela 1. Análise de solo.

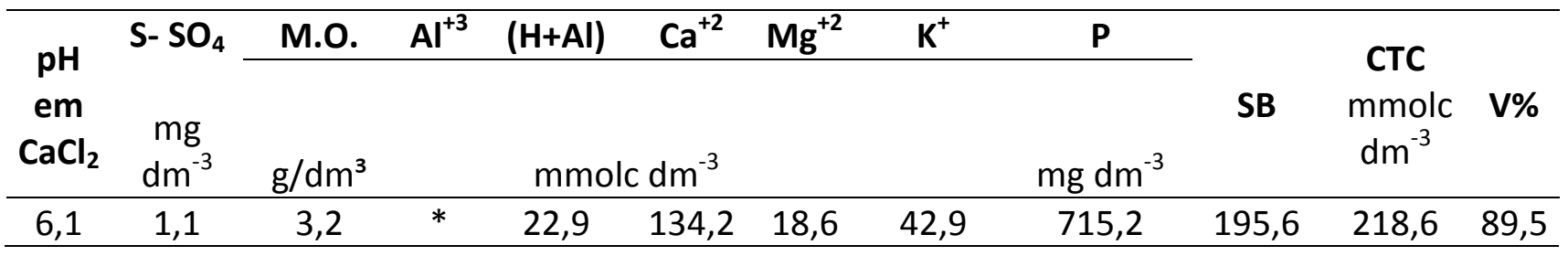

As lâminas de irrigação utilizadas foram: T1) $150 \%$, T2) $100 \%$, T3) $75 \%$, T4) $50 \%$ E T5) 25\% ETc (evapotranspiração da cultura). Para calcular a lâmina de irrigação foram realizadas leituras diárias no evaporímetro de Pichê, estimando a ETo (evapotranspiração de referência) e ajustando-se com o coeficiente de cultura (kc) de 1,2 (ALBUQUERQUE; RESENDE, 2009) (equação 01).

$E T c=E T o \times k c$ equação 01

Onde: ETc é a evpoatranspiração da cultura (mm); ETo é a evapotranspiração de referência $(\mathrm{mm})$ e kc é o coeficiente da cultura.

O experimento foi conduzido por um período de 80 dias após o plantio (DAP), ou seja, durante a fase de desenvolvimento vegetativo, segundo Fancelli (1991).

Os parâmetros avaliados foram altura de plantas (quinzenalmente); comprimento e volume de raiz, massa seca de parte aérea e raiz e concentração de prolina nas folhas frescas.

O volume de raízes de acordo com a metodologia de Basso (2001). A prolina foi determinada pela metodologia de Bates et al. (1973) modificada por Machado Neto et al. 
(2004), utilizando a ninidrina ácida e solução de prolina estoque para determinação da curva padrão.

Os dados foram submetidos a análise de variância (ANOVA) e posteriormente ao Teste Tukey ao nível de probabilidade de 5\% para comparação de médias.

\section{RESULTADOS E DISCUSSÃO}

Os dados de altura semanal do milho durante a fase vegetativa não apresentaram diferenças significativas para a interação entre lâminas de irrigação e cultivares, e para os fatores isolados.

Observou-se na tabela 2 que para a variedade Agroceres 8088 a lâmina de irrigação de $75 \%$ ETc favoreceu o maior desenvolvimento do sistema radicular. As lâminas com déficit hídrico de 25 e 50\%ETc apresentaram os menores valores para o volume de raízes.

A variedade PEN 22 Robusta não apresentou diferenças no volume de raízes considerando as diferentes lâminas de irrigação aplicadas.

Avaliando-se a interação entre lâmina de irrigação e variedade verificou-se que a variedade de milho PEN 22 Robusto apresentou menores valores de volume de raiz à medida que aumentou a quantidade de água aplicada. A irrigação com $25 \%$ da ETc resultou na maior concentração de raízes no solo. Em situação de baixa disponibilidade de água algumas plantas tendem a aumentar o desenvolvimento do sistema radicular como alternativa para captar água de regiões mais profundas no perfil do solo.

Solo de classe textural arenosa apresentando alta velocidade de infiltração e tendência a perdas por percolação, para atender a necessidade hídrica as raízes tendem a aumentar a elongação celular em busca de água (TAIZ; ZEIGER, 2013; SCOPEL et al., 2013).

O transgênico Agroceres 8088 apresentou os maiores volumes de raízes para as lâminas de irrigação $25 \%$ e $50 \%$ ETc (déficit hídrico) e 150\% ETc (excesso hídrico). Por se tratar de um transgênico, apresenta características morfológicas que favorecem a adaptação em diferentes ambientes, o aumento do desenvolvimento do sistema radicular é uma das alternativas a condições de estresse abiótico (CRUZ, 2013). 
Tabela 2. Volume de raiz $(\mathrm{mL}$ ) para as duas variedades de milho (Agroceres 8088 e PEN 22 robusto) submetidas a diferentes lâminas de irrigação.

\begin{tabular}{cccccc}
\hline & \multicolumn{5}{c}{ Lâmina de irrigação (ETc \%) } \\
Variedades & 25 & 50 & 75 & 100 & 150 \\
\cline { 2 - 6 } $\begin{array}{c}\text { Agroceres } \\
8088\end{array}$ & $10,0 \mathrm{Ba}$ & $11,3 \mathrm{Ba}$ & $16,3 \mathrm{Aba}$ & $15,0 \mathrm{Aba}$ & $20 \mathrm{Aa}$ \\
$\begin{array}{c}\text { PEN 22 } \\
\text { Robusto }\end{array}$ & $7,5 \mathrm{Aa}$ & $5,75 \mathrm{Ab}$ & $8,3 \mathrm{Ab}$ & $8,4 \mathrm{Ab}$ & $6,3 \mathrm{Ab}$ \\
\hline
\end{tabular}

As letras minúsculas comparam as médias nas colunas e as maiúsculas comparam as médias na linhas pelo teste Tukey.

Para a massa seca de parte aérea (Tabela 3) foi possível observar que variedade PEN 22 Robusta apresentou maior massa quando irrigada com a menor quantidade de água (25\% ETc). O Agroceres 8088 acumulou maior massa seca de parte aérea a partir da reposição de $50 \%$ ETc. É possível verificar que a variedade PEN 22 Robusta apresenta mais rusticidade que a
Agroceres 8088, pois necessita de menor quantidade de água para investir no acúmulo de biomassa de parte aérea.

De acordo com Silva et al. (2012), o cultivar Agroceres 8088 apresentou elevada demanda evapotranspiratória para aumentar a produtividade de biomassa seca de parte aérea para o milho, destacando-se a lâmina de irrigação de $100 \%$ ETc.

Tabela 3. Massa seca de parte aérea para as duas variedades de milho (Agroceres 8088 e PEN 22 robusto) submetidas a diferentes lâminas de irrigação.

\begin{tabular}{cccccc}
\hline & \multicolumn{4}{c}{ Lâmina de irrigação (ETc \%) } \\
Variedades & 25 & 50 & 75 & 100 & 150 \\
\cline { 2 - 6 } $\begin{array}{c}\text { Agroceres } \\
8088\end{array}$ & $2,9 \mathrm{BCa}$ & $5,5 \mathrm{Aa}$ & $2,8 \mathrm{Ca}$ & $5,8 \mathrm{Aa}$ & $5,3 \mathrm{Aba}$ \\
$\begin{array}{c}\text { PEN 22 } \\
\text { Robusto }\end{array}$ & $1,4 \mathrm{Aa}$ & $1,1 \mathrm{Ab}$ & $1,5 \mathrm{Aa}$ & $2,08 \mathrm{Ab}$ & $1,3 \mathrm{Ab}$ \\
\hline
\end{tabular}

As letras minúsculas comparam as médias nas colunas e as maiúsculas comparam as médias na linhas pelo teste Tukey.

Verificou-se para os dados de massa seca de raiz (Tabela 4) que as lâminas de irrigação de $25 \%$, 50\% e $75 \%$ apresentaram os maiores resultados de massa seca de raiz quando comparadas as variedades estudadas. Resultado esse que reflete 0 maior volume de raízes para Agroceres 8088 (Tabela 2). Embora a variedade PEN 22 Robusto não tenha apresentado os maiores volumes de raízes para essas lâminas, a maior massa seca de raiz pode ter ocorrido em decorrência da formação de raízes de maior 
calibre e com maior número de pelos absorventes para favorecer o aumento da absorção da menor quantidade de água aplicada (TAIZ; ZEIGER, 2013; COELHO et al., 2013).

Tabela 5. Massa seca de raiz para as duas variedades de milho (Agroceres 8088 e PEN 22 robusto) submetidas a diferentes lâminas de irrigação.

\begin{tabular}{cccccc}
\hline & \multicolumn{5}{c}{ Lâmina de irrigação (ETc \%) } \\
Variedades & 25 & 50 & 75 & 100 & 150 \\
\cline { 2 - 6 } $\begin{array}{c}\text { Agroceres } \\
8088\end{array}$ & $1,4 \mathrm{Ca}$ & $2,1 \mathrm{BCa}$ & $2,0 \mathrm{BCa}$ & $3,9 \mathrm{ABa}$ & $4,2 \mathrm{Aa}$ \\
$\begin{array}{c}\text { PEN 22 } \\
\text { Robusto }\end{array}$ & $1,4 \mathrm{Aa}$ & $1,2 \mathrm{Aa}$ & $1,4 \mathrm{Aa}$ & $1,4 \mathrm{Ab}$ & $1,1 \mathrm{Ab}$ \\
\hline
\end{tabular}

As letras minúsculas comparam as médias nas colunas e as maiúsculas comparam as médias nas linhas pelo teste Tukey.

Para a concentração de prolina nas folhas frescas (Tabela 5) não houve interação entre os fatores estudados. No entanto, avaliando-se os dados de prolina para cada lâmina de irrigação detectou-se que a lâmina de irrigação de $25 \%$ ETc foi a restrição hídrica que promoveu maior concentração de prolina no desenvolvimento vegetativo do milho. O aminoácido prolina é um marcador molecular de estresse hídrico, portanto em situações de baixa disponibilidade hídrica há uma tendência do aumento da sua concentração nas células vegetais (SANTOS et al., 2010).

Tabela 4. Efeito isolado das lâminas de irrigação na concentração de prolina $\left(\mu L^{-1}\right)$ nas folhas frescas de milho.

\begin{tabular}{cc}
\hline Lâmina de irrigação (\%ETc) & Prolina $\left(\mu \mathrm{L} \mathrm{L}^{-1}\right)$ \\
\hline 25 & $8,56 \mathrm{a}$ \\
50 & $5,95 \mathrm{ab}$ \\
75 & $4,42 \mathrm{bc}$ \\
100 & $1,56 \mathrm{~cd}$ \\
150 & $0,57 \mathrm{~d}$ \\
\hline
\end{tabular}

As letras minúsculas comparam as médias entre os tratamentos de lâminas de irrigação pelo teste Tukey. 


\section{CONCLUSÃO}

Para as condições do Oeste Paulista, é mais viável o plantio do cultivar da PEN 22 Robusta irrigado com $25 \%$ da ETc.

\section{REFERÊNCIAS}

ALBUQUERQUE, P.E.P.; RESENDE, M. Manejo de irrigação. In: CRUZ, J.C. (eds.). Cultivo do milho. 5. ed. Sete Lagoas: Embrapa Milho e Sorgo, 2009.

BASSO, S.M.S. Caracterização morfológica e fixação biológica de nitrogênio de espécies de Adesmia latifolia e Lótus corniculatus em vasos de Leonard. Revista Brasileira Zootécnica, v.30, n.687-693, 2001.

BATES, L., WALDREN, R.P., TEARE, I.D. Rapid determination of free proline for water-stress studies. Plant and Soil, v.39, p.205-207, 1973. http://dx.doi.org/10.1007/BF00018060

BENJAMIN, J.G.; NIELSEN, D.C.; VIGIL, M.F.; MIKHA, M.M.; CALDERON, F. Water deficit stress on corn (Zea mays, L.) Root: Shoot ratio. Journal of Soil Science, v.4, p.151-160, 2014.

BRITO, M.E.B.; FILHO, G.D.A.; WANDERLEY, J.A.C.; MELO, A.S.; COSTA, F.B.; FERREIRA, M.G.P. Crescimento, fisiologia e produção do milho doce sob estresse hídrico. Bioscience Journal, v.29, n.5, p.1244-1254, 2013.

CARMO, M.S.; CRUZ, S.C.S.; SOUZA, E J.; CAMPOS, L.F.C.; MACHADO, C.G. Doses e fontes de nitrogênio no desenvolvimento e produtividade da cultura do milho doce (Zea mays convar. saccharata var. rugosa). Bioscience jornal, v.28, supl.1, p.223-231, 2012.

COELHO, C.C.R.; SILVA, J.N.; NEVES, M.G.; CONCEIÇÃO, A.G.C.; SILVA, R.T.L.; OLIVEIRA NETO, C.F. Aspectos ecofisiológicos e crescimento em plantas de milho submetidos ao alagamento. Revista Agroecossistemas, v.5, n.2, p.41-46, 2013.

CRUZ, S.J.S. Características morfológicas de plantas e produtividade do milho. 2013. Tese (Doutorado) -UNESP, Jaboticabal - SP.

EMBRAPA/ Centro Nacional de Pesquisa de Solos. Sistema brasileiro de classificação de solos. Brasília, DF: Embrapa Produção da Informação, 1999. 412 p.

FANCELLI, A. L. Milho e feijão: Elementos de manejo em agricultura irrigada. Fertirrigação: Algumas considerações. Piracicaba: ESALQ, 1991. p.156-167.

FERREIRA, M.G.P.; BRITO, M.E.B.; COSTA, F.B.; ARAÚJO FILHO, G.D.A. ; ALVINO, F.C.G. Aspectos físicos e químicos dos grãos de milho doce sob estresse hídrico. Revista Brasileira de Agrotecnologia, v.1, n.1, p.0106, 2011.

LOPES, A.S.; OLIVEIRA, G.Q.; SOUTO FILHO, S.N.; GOES, R.J.; CAMACHO, M.A. Manejo de irrigação e nitrogênio em feijoeiro comum cultivado em sistema de plantio direto. Revista Ciência Agronômica, v.42, n.1, p.5156, 2011. http://dx.doi.org/10.1590/S180666902011000100007

MACHADO NETO, N.B., CUSTÓDIO, C.C., GATTI, A.B., PRIOLLI, M.R., CARDOSO, V.J.M. Proline: use as indicator of temperature stress in bean seeds. Crop Breeding and Applied Biotechnology, v.4, p.127-134, 2004. http://dx.doi.org/10.12702/1984-

7033.v04n03a11

PAVINATO, P.S.; CERETTA, C.A.E.; GIROTTO, C.A.E.; MOREIRA, I.C.L. Nitrogênio e potássio em milho irrigado: análise técnica e econômica da fertilização. Ciência Rural, Santa Maria, v.38, n.2, p.358-364, 2008. http://dx.doi.org/10.1590/S0103$\underline{84782008000200010}$

SANTOS, C.F.; LIMA, G.P.P.; MORGADO, L.B. Tolerância e caracterização bioquímica em 
feijão submetido ao estresse hídrico na préfloração. Naturalia, v.33, p.34-44, 2010.

SCOPEL, I.; SOUSA, M.S.; MARTINS, A.P. Infiltração de água e potencial de uso de solo muito arenosos nos cerrados. Boletim Goiano de Geografia, v.33, n.2, p.45-61, 2013.

http://dx.doi.org/10.5216/bgg.v33i2.25556

SILVA, M.R.R.; VANZELA, L.S.; VAZQUEZ, G.H.; SANCHES, A.C. Influência da irrigação e cobertura morta do solo sobre as características agronômicas e produtividade do milho. Irriga, p.170-180, 2012.

TAIZ, L.; ZEIGER, E. Fisiologia Vegetal. $5^{\circ}$ ed., Porto Alegre, 2013, $918 \mathrm{p}$.

VAN RAIJ, B., CANTARELLA, H., QUAGGIO, J.A., FURLANI, A.M.C. Recomendações de adubação e calagem para o Estado de São Paulo, $2^{\circ}$ ed., Campinas, 1997, 285 p. 